\title{
Engineering Aspergillus terreus Metabolic Pathways to Increase Lovastatin Production via Metabolic Engineering and Fermentation Approaches
}

\author{
Hanan Hasan ${ }^{1}$, Muhammad Hafiz Abd Rahim ${ }^{1}$, Leona Campbell ${ }^{2}$, Dee Carter ${ }^{2}$, Ali \\ Abbas $^{2,3}$, and Alejandro Montoya ${ }^{3}$ \\ ${ }^{1}$ University Putra Malaysia \\ ${ }^{2}$ University of Sydney \\ ${ }^{3}$ The University of Sydney
}

June 23, 2020

\begin{abstract}
This study explores the application of metabolic engineering in Aspergillus terreus to re-route the precursor flow towards the lovastatin biosynthetic pathway by simultaneously overexpressing the gene for acetyl-CoA carboxylase (acc) to increase the precursor and eliminating (+)-geodin biosynthesis (competing metabolite), by knocking out emodin anthrone polyketide synthase $($ ged $C)$. Alterations to metabolic flux in the double mutant $\left(\gamma \in \delta^{\circ \prime} \Delta^{*} a \varsigma \varsigma \sigma_{\zeta}\right)$ strain and the effects of using two different substrate formulations were examined. Cultivation of $\gamma \in \delta^{\prime \prime} \Delta^{*} a \varsigma \varsigma o \xi$ strain with a mixture of glycerol and lactose, had greatly increased levels of precursors malonyl-CoA (48\%) and acetyl-CoA (420\%), complete inhibition of $(+)$-geodin biosynthesis and a maximum production of lovastatin $(152 \mathrm{mg} / \mathrm{L}), 143 \%$ more than the wild-type (WT) strain. This study demonstrates the manipulation of $A$. terreus metabolic pathways to increase the efficiency of carbon flux towards lovastatin, elevating its production. It provides a framework for new opportunities to synthesize valuable compounds using cheap and renewable carbon sources.
\end{abstract}

\section{Hosted file}

Hasan et. al 2020 Manuscript.docx available at https://authorea.com/users/336007/articles/ 461829-engineering-aspergillus-terreus-metabolic-pathways-to-increase-lovastatin-

production-via-metabolic-engineering-and-fermentation-approaches 


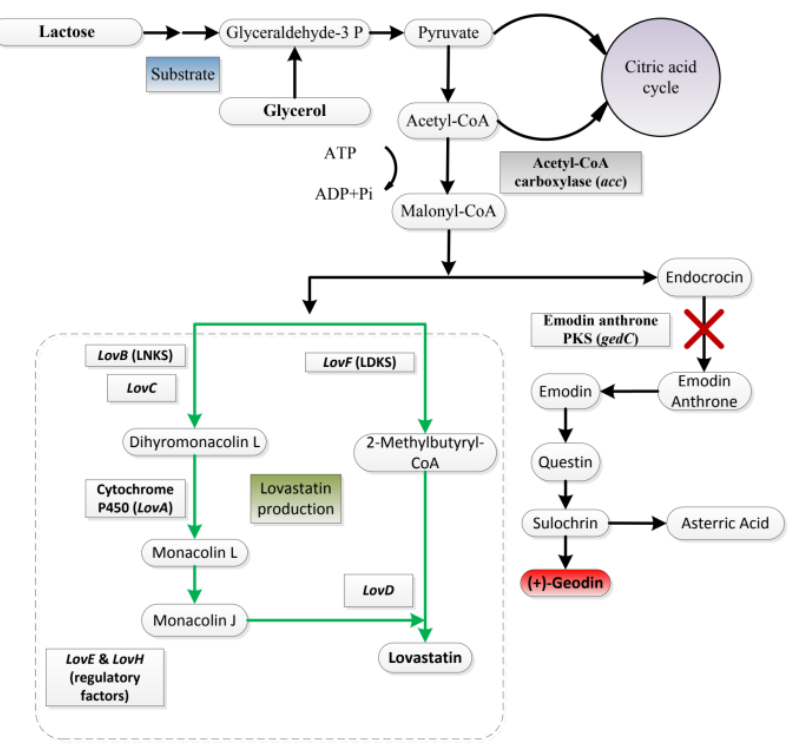




\section{Glycerol Substrate}
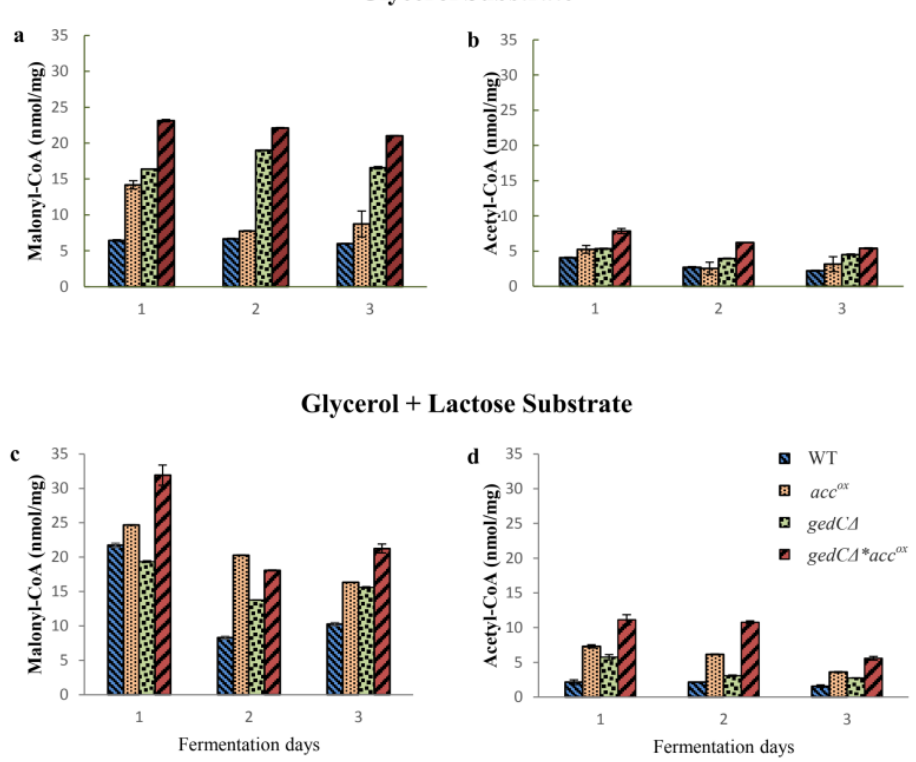
Glycerol Substrate
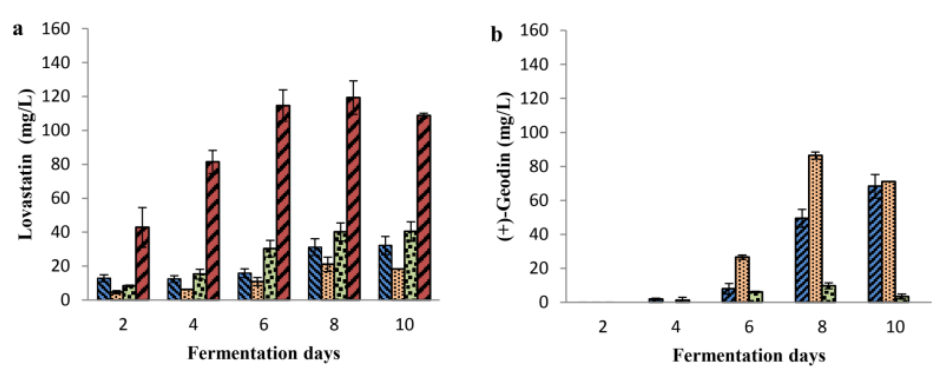

Glycerol + Lactose Substrate
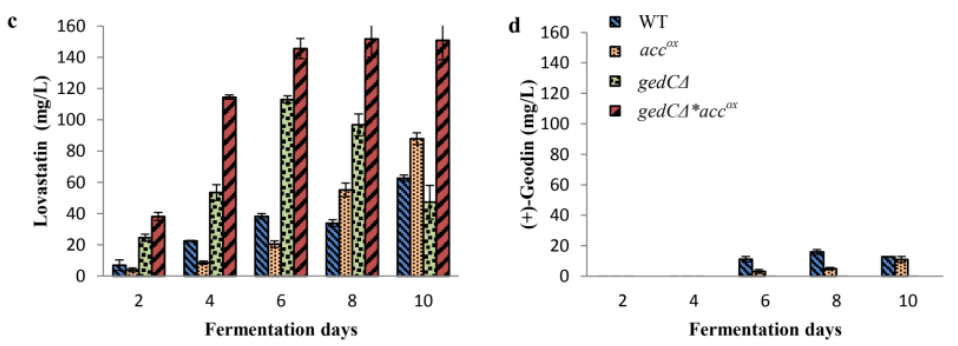
Glycerol Substrate

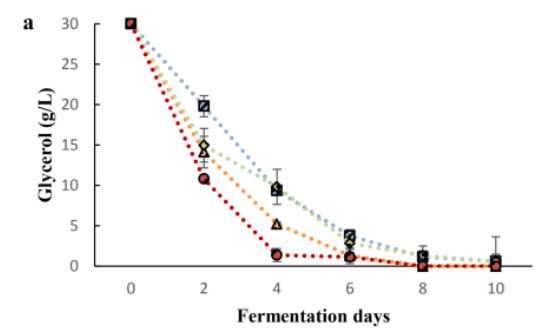

Glycerol + Lactose Substrate
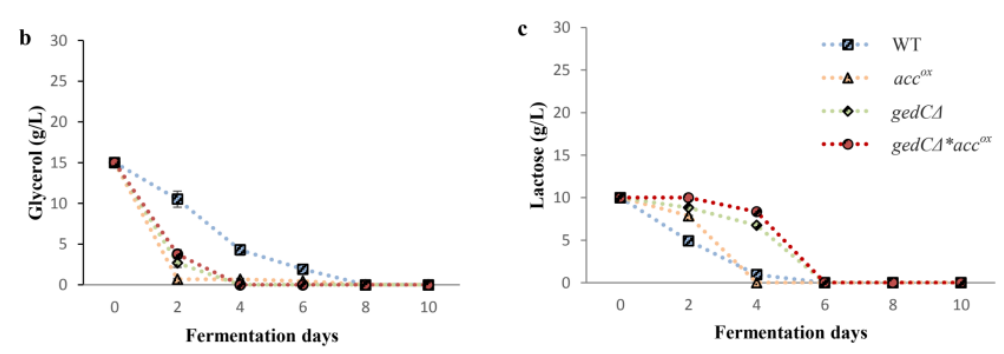